\title{
Representatividade feminina em 40 anos da Revista Brasileira de Ensino de Física
}

\author{
Female representation in 40 years of the Revista Brasileira de Ensino de Física
}

\author{
Érica Cupertino Gomes ${ }^{10}$, Sheyse Martins de Carvalho ${ }^{*}\left[{ }^{0}\right.$, Alexsandro Silvestre da Rocha ${ }^{1}$ \\ ${ }^{1}$ Universidade Federal do Tocantins, Curso de Física, Araguaína, TO, Brasil.
}

Recebido em 16 de março de 2021. Aceito em 11 de abril de 2021.

\begin{abstract}
Esta é uma breve nota ao editor, em função do importante marco de 2019 para a Revista Brasileira de Ensino de Física (RBEF), por se tratar do seu aniversário de 40 anos. Em função dessa referência e do aumento de pesquisas envolvendo a representatividade feminina nas Ciências no âmbito acadêmico, os autores dessa carta realizaram um mapeamento do perfil das autorias dos artigos científicos na revista ao longo desses 40 anos. Percebe-se, com base nos dados apresentados, o aumento da participação feminina como autoras de trabalhos e um amplo espaço para crescimento.

Palavras-chave: Participação Feminina, Pesquisa, Física.
\end{abstract}

\begin{abstract}
This is a brief note to editor, due to the important milestone of 2019 for the Revista Brasileira de Ensino de Física (RBEF), as it is its 40th anniversary. Due to this reference and the increase in research involving female representativeness in the sciences in the academic sphere, the authors of this letter have mapped the profile of the authorship of scientific articles in the journal over these 40 years. Based on the data presented, there is an increase in female participation as authors of works and there is ample room for growth.
\end{abstract}

Keywords: Female Participation, Research, Physics.

A Revista Brasileira em Ensino de Física (RBEF) é uma publicação consolidada, que busca a melhoria do ensino de Física e vinculada à Sociedade Brasileira de Física (SBF). É o periódico brasileiro mais antigo e de acesso livre, dedicado a publicar temas relevantes para o ensino de Física.

A RBEF, desde a criação em 1979 e ao longo dos 40 anos, até o quarto artigo da quarta edição do $41^{\circ}$ volume, tem aproximadamente 2200 artigos publicados com um total de 4782 autores associados a esses trabalhos.

Em associação com essa recordação, existe um movimento importante e pertinente, associado ao fomento da participação feminina no campo das Ciências, especificamente no âmbito acadêmico. Alguns estudos apontam para o crescimento da participação feminina em cursos de graduação ligados à área das Ciência. A Elsevier [1, produziu um relatório que constata que o número de pesquisadoras mulheres no Brasil aumentou significativamente nos últimos anos e representam cerca de $49 \%$ dos pesquisadores brasileiros, em dados avaliados entre 2011 e 2015 pela revista. O mesmo levantamento constata que, quanto ao número de citações e importações eletrônicas (downloads) dos trabalhos científicos, existe equidade entre homens e mulheres no Brasil. Entretanto, quando olhamos especificamente para a área de Física este cenário não se repete, as mulheres estão sub-representadas e abrangem menos de

\footnotetext{
*Endereço de correspondência: sheysemartins@uft.edu.br
}

$25 \%$ do número de pesquisadores. Estudos comprovam que o número de pesquisadoras ainda é bastante inferior ao número de pesquisadores, especialmente nesta área 2 e que esta pouca representatividade é cada vez mais evidente conforme se avança na carreira.

Pensando na trajetória da RBEF e nesse movimento extremamente importante, os autores pensaram em investigar a participação feminina nas pesquisas publicadas na Revista Brasileira em Ensino de Física.

\section{Anos de RBEF em Números Associados ao Quantitativo de Autores}

Com base em uma pesquisa bibliográfica no site da RBEF, foi possível analisar o quantitativo de pesquisadores autores por gênero e por região do país ao longo dos 40 anos de publicação da revista. Os resultados são apresentados sob uma perspectiva algébrica e descritiva.

Ao direcionarmos nossos esforços para o objetivo, destacamos o gráfico apresentado na Figura 1 que segrega os autores por gênero, descrevendo o quantitativo ao longo dos anos.

No gráfico (Figura 1) mostramos em vermelho o número total de autoras (mulheres) e em preto os homens (autores), independentemente da ordem autoral. Nota-se na Figura 1 que entre 1979 até 1995 os patamares entre homens e mulheres eram praticamente os mesmos, mas após este período os autores masculinos 


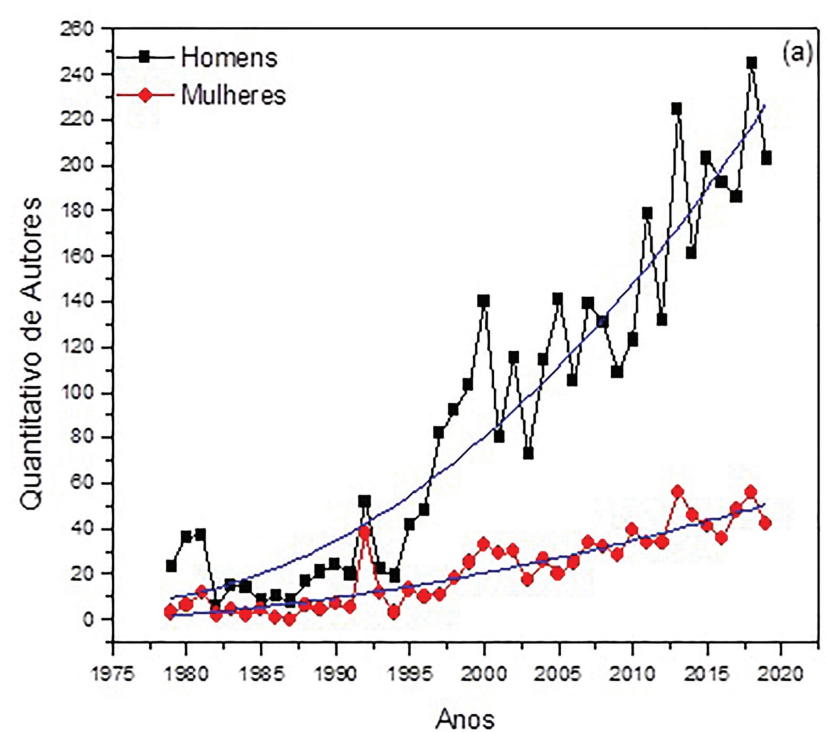

Figura 1: Quantitativo de homens e mulheres que publicaram na RBEF ao longo dos anos.

aumentaram drasticamente. A diferença de autorias chega a 6 vezes mais pesquisadores homens. Mesmo com uma diferença grande entre os gêneros, percebe-se que o processo de crescimento é ascendente e possui as mesmas características gráficas.

Partindo do fato de que a RBEF é uma revista internacional, mas voltando o olhar para as regiões do Brasil, é possível observar que os autores ao longo desses 40 anos são em maioria da Região Sudeste do país (mais de $50 \%$ ), seguido pela Região Sul (cerca de $17 \%$ ). A Região Norte concentra o menor percentual de pesquisadores que publicam na revista, cerca de $3 \%$, e como destaque temos o estado do Tocantins, tendo em vista que nenhuma pesquisadora do estado publicou na RBEF ao longo desses 40 anos de jornada.

Embora existam diversos periódicos com foco e escopo semelhantes à RBEF, entendemos que ela é representativa, em função de sua importante trajetória no país. Os dados analisados demonstraram que alguns anos foram atípicos, mas claramente a revista se fortaleceu ao longo dos 40 anos e hoje é uma referência.

Nesse sentido, os dados analisados demonstraram a pouca representatividade feminina nas autorias de artigos publicados na revista. Mesmo havendo um aumento da participação feminina, essa participação ainda é pequena e cresce muito lentamente. Analisando por região é possível perceber que existe amplo espaço para o crescimento, principalmente nas regiões norte e nordeste.

Entendemos que esse breve estudo não representa o quantitativo de pesquisadoras em Física no Brasil, mas é pertinente para ilustrar o cenário nacional, tendo em vista que os dados são coerentes com estudos sobre o tema. É importante refletir e incentivar mais mulheres a adentrarem para o campo das ciências, especialmente Físicas.

\section{Referências}

[1] Elsevier, Gender in the Global Research Landscape, disponível em: https://www.elsevier.com/research-in telligence/campaigns/gender-17

[2] E.M.B. Saitovitch, M.C. Barbosa, R.Z. Funchal, S.T.R. Pinho e A.E. Santana, AIP Conference Proceedings 1697, 060007 (2015). 